\title{
The Study of the Supernormal Mechanical Properties of Giant NPR Anchor Cables
}

\author{
ZhiGang Tao $\mathbb{D}^{1,2}$ HuiXia Xu, ${ }^{1,2}$ Chun Zhu $\mathbb{D}^{1,2,3}$ Qian Lv, ${ }^{1,2}$ and Yong Wang ${ }^{1,2}$ \\ ${ }^{1}$ State Key Laboratory for Geomechanics and Deep Underground Engineering, Beijing 100083, China \\ ${ }^{2}$ School of Mechanics and Civil Engineering, China University of Mining and Technology, Beijing 100083, China \\ ${ }^{3}$ College of Construction Engineering, Jilin University, Changchun 130026, China \\ Correspondence should be addressed to ZhiGang Tao; taozhigang@263.net and Chun Zhu; zhuchuncumtb@163.com
}

Received 5 December 2019; Revised 14 January 2020; Accepted 30 January 2020; Published 16 March 2020

Academic Editor: Marco Gherlone

Copyright (c) 2020 ZhiGang Tao et al. This is an open access article distributed under the Creative Commons Attribution License, which permits unrestricted use, distribution, and reproduction in any medium, provided the original work is properly cited.

\begin{abstract}
Due to the frequent occurrence of geological disasters, such as geological faults, tectonic activities, and local activities, the study of a cable structure capable of resisting large deformations and of absorbing energy is investigated. The plane length is increased step by step based on the deformation and energy absorption values of the original NPR anchor cable model. Three kinds of two-stage constant resistance bodies are designed following the three principles: first-stage friction plus second-stage expansion, primary expansion plus secondary expansion, and first-stage expansion plus second-stage friction. Moreover, a giant NPR anchor cable with extraordinary mechanical properties is developed. Via a theoretical analysis and laboratory static tensile tests on traditional NPR and giant NPR anchor cables, their force characteristics, constant resistance, and fluctuation trends are related to the size and the structure of the constant resistance body. In addition, the most remarkable improvement takes place in the cables' deformation and energy absorption properties. The deformation increases from $1000-2000 \mathrm{~mm}$ to $3000-4000 \mathrm{~mm}$, while the energy absorption value increases from $4.21 \times 10^{5}-1.09 \times 10^{6} \mathrm{~J}$ to $3.2 \times 10^{6} \mathrm{~J}$. The constant resistance value is also effectively enhanced to 550-723.7 kN. This provides a reliable technical support for their application in deep geological faults.
\end{abstract}

\section{Introduction}

Bolt support technologies are widely used in the field of slope reinforcement and support-based techniques, due to their abilities in improving the structural strength of the rock mass and in enhancing the slope stability [1-3]. However, when the depth of an excavation increases, geological disasters, such as large deformations mostly caused by landslides, cannot be avoided by employing traditional small-deformation support systems. This is due to complex factors, such as the high ground stress, rainfalls, and the weather condition, reducing the physical and mechanical properties of rock, which can easily cause slope instabilities and other secondary disasters [4-9]. In recent years, support materials with the characteristics of anchor bolt cables have been developed by several research groups in various countries. According to the working characteristics of three types of such anchor bolts, one can classify them as follows: strength bolts, yield bolts, and energy absorption bolts [10]. The supporting force of strength bolts is equal, or almost close, to the strength of the bolt material [11]. Yield bolts have a strong resistance against possible large deformations of the rock mass, despite their strength is small [12]. Energy absorption bolts allow one to obtain around $200-300 \mathrm{~mm}$ deformation of the rock mass upon maintaining the upper strength of the surrounding rock $[13,14]$. The tensile process with elastic deformationstrain hardening-strain softening was related to the use of energy absorption bolts with an increased working resistance upon a change in the rock deformation, and it appears that all the three anchors hardly meet the large deformation factors caused by slope instabilities and the 
needed control requirements. Currently, the traditional prestressed anchor cable systems and their derivatives retain structures. Their working principle mostly relies on their reinforcement and on the monitoring of the slope height and steepness $[15,16]$. It is urgent to develop new supporting cables with extraordinary mechanical properties in sight of the limitations in the mechanical properties of traditional bolts (cables) and of the severity of the engineering environmental problems. In the 1980s, the negative Poisson's ratio, or the auxetic material, was firstly discovered by Evans and Alderson [17]. In recent years, a series of negative Poisson's ratio materials have been developed [18-20]. In 2009, constant resistance and large deformation bolts with a negative Poisson's ratio structure were developed by Manchao et al. [21]. These cables show excellent characteristics, such as a high constant resistance. Moreover, their large deformation and strong energy absorption factors avoid the "necking failure" defect of traditional bolts [22]. The tension and displacement curves of the monitoring anchor cables in function of the highconstant resistance landslide were acquired via displacement-control experiments. These measurements aim to monitor the high-constant resistance landslide anchor cable and to reveal the behavior of the constant resistance and the displacement change [23]. Yang et al. [24] and Man-Chao et al. [25] successfully applied the results based on the NPR bolts' static tensile test to monitor the stability of open-side mine slopes, where the monitoring and warning effects were very significant. Nowadays, this type of anchor cable is mainly used to monitor and evaluate slope engineering processes and a few shallow active faults. Despite their constant resistance values, the cable deformations and their energy absorption characteristics do not manage to monitor and warn the existing complex geological hazards. In order to predict the tectonic activity of deep geological faults and to control the local geological activity faults, a giant NPR anchor cable was developed by Man-Chao et al. The deformation and constant resistance values of this anchor cable increased step by step up to $3000-4000 \mathrm{~mm}$ and $550-723.7 \mathrm{kN}$ (the maximum constant resistance is $567.7-800 \mathrm{kN}$ ). Moreover, an energy absorption value is observed in the range of $4.21 \times 105-1.09 \times 106 \mathrm{~J}$ for the NPR cables and of $3.2 \times 106 \mathrm{~J}$ for the giant NPR cables. The redesign of the structure of the constant resistance body to define the mechanical properties of the new constant resistance and its changes for NPR anchor cables showed to be consistent with the measured and calculated values, and this ensures the stability of the constant resistance.

\section{Design of Giant NPR Anchor Cable Structure}

2.1. Structure Composition of the NPR Anchor Cable. As shown in Figure 1, the NPR anchor cable is composed of a conical constant resistance body (installed inside a constant resistance device), a steel strand (1-7 pieces), a constant resistance sleeve (cylindrical device), a gasket (used for

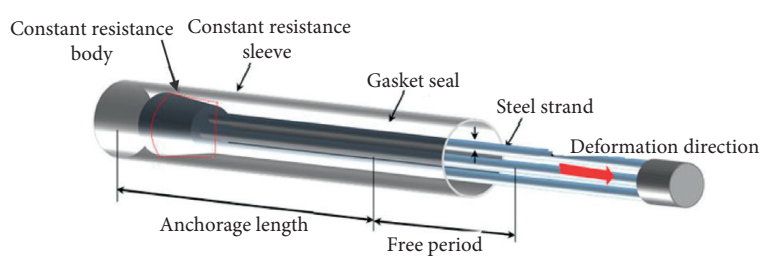

FIGURE 1: Schematic diagram of the NPR anchor.

sealing both ends of the constant resistance device), and a prestressed pallet (bearing tensile load). When the prestressed pallet and the steel strand are subjected to a tensile load, the relative movement between the cone and the sleeve transfers the load to the constant resistance body via the steel strand. This movement is equivalent to the deformation of the anchor cable. The reverse resistance generated during the movement is equal to the constant resistance. When the cone slips within the sleeve, the bolt is extended in the axial direction, and it expands radially. Therefore, the NPR bolt can also be used as an NPR material or a macroscopic structure.

\subsection{Structural Mechanic Optimization of the NPR-3000- (4000-) Type Constant Resistance Body}

2.2.1. NPR-2000 Model Construction of the Constant Resistance Structure. The constant resistance, which is one of the three characteristics of NPR anchor cables, is widely investigated, and researchers have been trying to reveal its trend and to explore the factors that affect its size. They found that the constant working resistance of the NPR bolt is irrelevant, when one considers the external load, but it turns out to be fundamental to determine the structure parameters of the cone and the elastic parameters of the sleeve. A more realistic model of the NPR anchor cable elastic-plastic mechanics can be established based on results provided in this paper. On the one hand, the aim of this work is to verify the mechanical model. On the other hand, an in-depth analysis of several factors affecting the constant resistance of the core and their degree of influence on the mechanical structure is provided. Moreover, these results may guide the design of different structure sizes and shapes for various NPR anchor cables under different constant resistance requirements in future developments.

In Figure 2, the following notations are used: $F c$ : constant resistance; $b$ : outer radius of the sleeve; $a$ : inner radius of the sleeve (equivalent to the diameter at the smallest end of the cone); $N$ : normal stress inside the sleeve; $P$ : compressive stress inside the sleeve; $R_{h}$ : end radius of the cone; $L g$ : length of the cone in contact with the sleeve; $\alpha$ : cone angle; $F_{f}$. friction between the inclined cone and the inner surface of the sleeve; $z_{1}$ : length of the constant resistance body corresponding to the elastic phase of the constant resistance device; $z_{2}, z_{3}$ : constant resistance body length corresponding to the plastic phase of the constant resistance device; $\Delta \delta$ : limit resilience value of the constant resistance body; $\delta$ : maximum swelling 


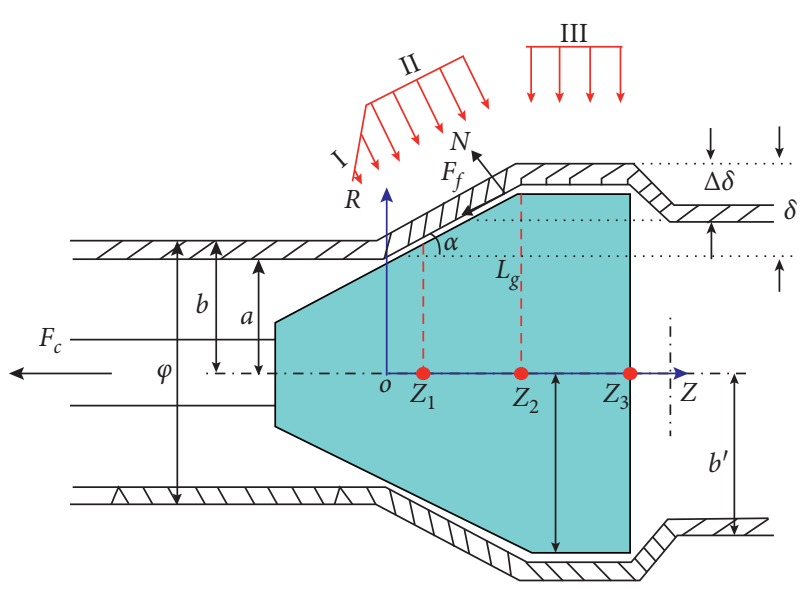

Figure 2: Mechanics analysis of the NPR-2000 model.

capacity of the constant resistance body; $\sigma_{\theta}$ : circumferential stress of the constant resistance body; $\sigma_{z}$ : axial stress of the constant resistance body; and $\sigma_{R}$ : radial stress of the constant resistance body.

(1) Two-dimensional plastoelasticity mechanical mode for an NPR bolt: when the two-dimensional plane hypothesis is applied to the analyzed NPR anchor cables, the plane strain assumption is introduced without taking into account the axial stress and the tangential strain. The axial stress and radial stress of the constant resistance body can be calculated via the equations $\sigma_{z}=\left(\sigma_{\theta}+\sigma_{R}\right) / 2$ and $1.155 \sigma_{S}=\sigma_{\theta}-\sigma_{R}$ and the following lame formulas [26]:

$$
\left.\begin{array}{l}
\sigma_{R}=\frac{P a^{2}}{b^{2}-a^{2}}\left(\frac{b^{2}}{R^{2}}-1\right) \\
\sigma_{\theta}=-\frac{P a^{2}}{b^{2}-a^{2}}\left(\frac{b^{2}}{R^{2}}-1\right) \\
\sigma_{Z}=0, \tau_{Z R}=0 \\
u_{R}=-\frac{P a}{E}\left[\frac{(1-\mu) a R}{b^{2}-a^{2}}+\frac{(1-\mu) a b^{2}}{b^{2}-a^{2}} \frac{1}{R}\right]
\end{array}\right\}
$$

For any position in the sleeve, as long as the stress $\left(\sigma_{\theta}-\sigma_{\mathrm{R}}\right)$ reaches the value of $1.155 \sigma_{S}$, the point meets the plastic state. As it can be seen from Figure 2, the inner diameter $(\mathrm{R}=a)$ enters initially the plastic state.

(2) Three-dimensional plastoelasticity mechanical mode of the NPR bolt: in this model, the stress-strain radial relationships with the circumferential and axial constant resistance body are taken into account. The stress component for the axisymmetric elastic mechanics of the space can be expressed by the Love displacement function, without considering any physical force, as follows [27]:

$$
\left.\begin{array}{l}
\sigma_{R}=\frac{\partial}{\partial z}\left(\mu \nabla^{2}-\frac{\partial^{2}}{\partial R^{2}}\right) \phi \\
\sigma_{\theta}=\frac{\partial}{\partial z}\left(\mu \nabla^{2}-\frac{1}{R} \frac{\partial}{\partial R}\right) \phi \\
\sigma_{Z}=\frac{\partial}{\partial z}\left[(2-\mu) \nabla^{2}-\frac{\partial^{2}}{\partial z^{2}}\right] \phi \\
\tau_{Z R}=\frac{\partial}{\partial R}\left[(1-\mu) \nabla^{2}-\frac{\partial^{2}}{\partial z^{2}}\right] \phi \\
u_{R}=-\frac{1}{2 G} \frac{\partial^{2} \phi}{\partial R \partial z}
\end{array}\right\},
$$

where $G$ and $\mu$ are the shear modulus and the Poisson ratio, respectively, while $\phi$ is the harmonic function. According to Figure 2, the following boundary conditions were introduced: (1) $R=a$ and $\sigma_{\mathrm{R}}=P$; (2) $\tau_{R Z}=N f$; (3) $R=b$; (4) $\sigma_{R}=\tau_{R Z}=0$; (5) $z=0$ and $\sigma_{z}=0$; and (6) $z=l, \sigma_{z}=q$, and $q=2 f \mathrm{Nla} / b^{2}-a^{2}$. In these expressions, $f$ is the frictional coefficient, $l$ is the axial length of the constant resistance body, and $q$ is the axial stress at the fixed end of the sleeve (assuming that the axial stress is evenly distributed along the radial direction). According to the concept of a thick-wall cylinder, the ratio between the outer radius, $b$, and the inner radius, $a$, must be bigger than 1.2. This means that the geometric shape is symmetric along the central axis and along the axial direction of the cylinder. Moreover, this implies that the load distribution along the cylinder is also symmetric along the central axis. By applying the same calculation on the NPR anchor cable constant resistance (with $b / a=1.39$ ), one can notice that, along the axial constant resistance body, the geometric shape and the stress distribution center show an axial symmetry. This means that the NPR anchor cable is similar to a thick-wall cylinder with the radial stress $\sigma_{R}$ and axial stress $\sigma_{z}$. The circumferential stress, $\sigma_{\theta}$, and the shear stress, $\tau_{R Z}$, of the constant resistance body are also taken into account. In conclusion, the analytical solution of the $3 \mathrm{D}$ plastoelasticity mechanical model is closer to the actual constant resistance value than that of the 2D model for an NPR-2000 $\mathrm{mm}$ anchor cable.

2.2.2. Structural Optimization of an NPR-3000 (4000) Constant Resistance Body Type. In order to effectively improve the constant resistance of the NPR anchor cable and to ensure that this follows the same constant resistance fluctuation rule of the NPR anchor rod, a structural redesign was carried out on the constant resistance sleeve and on the constant resistance cone. Based on the characteristics of an NPR bolt, in which the monolithic tubular structure is $1000 \mathrm{~mm}$ and longer, this generates coaxial problems, which lead to a good resistance or to severe fluctuations in the 
constant resistance curve during the tensile process in NPR cables. To improve the design of the constant resistance cone structure, the internal structure of the constant resistance sleeve is modified to generate a problem. The analysis of the motion and of the deformation law of the constant resistance body during the tensile process for an NPR anchor cable shows that a spring-back state occurs in the radial direction of the constant resistance body. This results in the creation of a prismatic surface on the inner wall of the constant resistance sleeve (a convex structure), when the constant resistance cone reaches a certain position along the constant resistance sleeve, as shown in Figure 3.

In this work, a new type of constant resistance body was designed. It consists of a two-stage constant resistance body (as shown in Figure 4), which is built by making use of the convex structure in the inner wall of the NPR anchor cable constant resistance sleeve. The two-stage constant resistance body cannot increase the constant resistance of the NPR anchor cable alone. Despite this, it shows a uniform fluctuation rule.

The change of the constant resistance is analyzed, and the expression of the constant resistance is simplified as follows:

$$
F_{c}=F_{c 1}+F_{c 2}+F_{c 3}=A_{1} P f+A_{2} P f+A_{3} P f,
$$

where $A_{1}$ is the area of the constant resistance body during the elastic stage (inclined plane), $A_{2}$ is the area of the constant resistance body during the plastic stage (inclined plane), $A_{3}$ is the area of the constant resistance body during the plastic stage (plane), $P$ is the surface pressure of the constant resistance body, and $f$ is the frictional coefficient. Another relevant equation is $F c_{3}=A_{3} P f$, where $A_{3}=2 \pi L p$. When the pressure $(P)$ is increasing, $L_{P}$ can increase the third constant resistance value, thereby increasing the overall constant resistance value, as shown in Figure 5.

The constant resistance can be improved by increasing the plane length of the constant resistance cone appropriately, but this may cause an unnecessary waste if it exceeds a reasonable range. According to the actual situation (installation requirements and size ratio), the maximum length of the constant resistance body is defined to be $200 \mathrm{~mm}$ and the maximum plane length of the constant resistance body is $125 \mathrm{~mm}$.

\subsection{Development of an NPR-3000 (4000) Constant Resistance} Specimen. Based on the design of the NPR-2000 and the measurements of the deformation law of the core constant resistance body of an NPR anchor cable, three types of twostage constant resistance bodies are proposed, as shown in Figure 6.

Based on the single-stage constant resistance body, three new types of constant resistance bodies were designed. The working characteristics of the first type of two-stage constant resistance body are the following: The first-stage friction adds a second-stage expansion to the constant resistance body. This means that when the constant resistance cone slips in the constant resistance sleeve, the first level of the constant resistance cone mainly acts on the friction slip, and this only provides some friction on the NPR anchor cable.

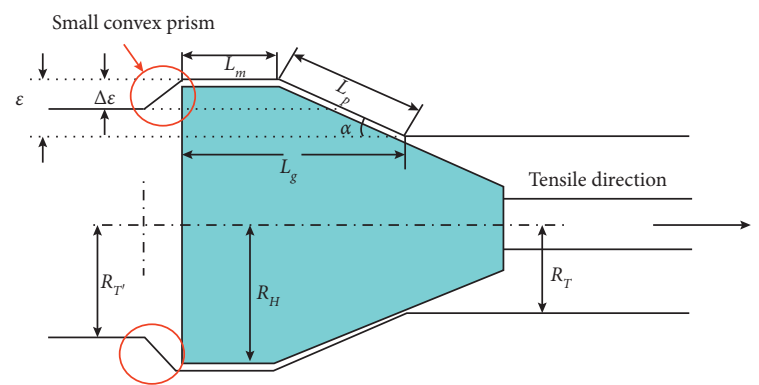

Figure 3: Deformation of the inner wall (NPR anchor constant resistor).

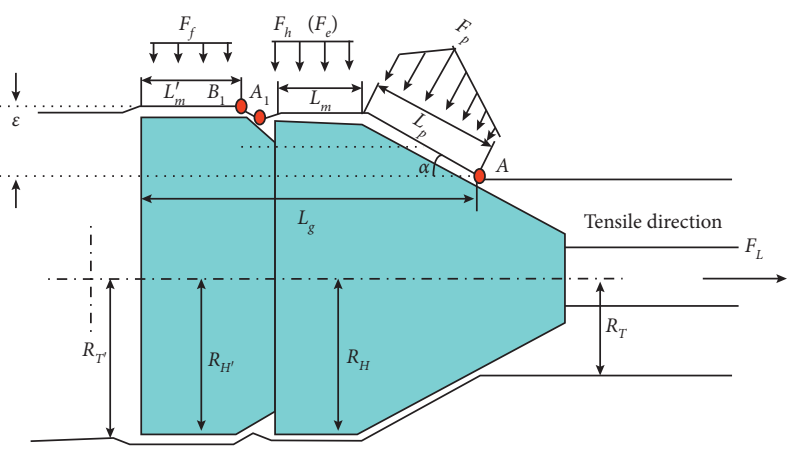

Figure 4: Two-stage constant resistance body.

The second level mostly generates an expansion during the movement and plays a role in increasing the friction in the process. The second type of two-stage constant resistance body is based on a primary and a secondary expansion. When the constant resistance cone slips in the constant resistance sleeve, the first level of the constant resistance body expands and then slides, generating an increase in the friction force. When the first expansion is complete, the second level starts expanding continuously and moves the constant resistance sleeve, generating a friction force. The third type of two-stage constant resistance body works based on a first-stage expansion and a second-stage friction. When the constant resistance cone slips in the constant resistance sleeve, the first stage of the constant resistance body expands and then slides to increase the friction force, while the second stage mainly generates the friction force. Although there exist different design methods and bipolar constant resistance body modifications, with the proposed techniques, the constant resistance was effectively improved and showed a certain trend in its fluctuation effect.

\section{Supernormal Static Tensile Test of the NPR- 3000 (4000) Anchor Cable}

Based on their deformation factor of about $2000 \mathrm{~mm}$, NPR anchor cables are currently used in slope engineering. Cables, which can deal with a deformation up to $3000 \mathrm{~mm}$ and $4000 \mathrm{~mm}$, also known as giant NPR anchor cables, are here investigated. They were adopted to carry out a static tensile test, in order to enhance their deformation and energy absorption ability. Moreover, new working conditions as 


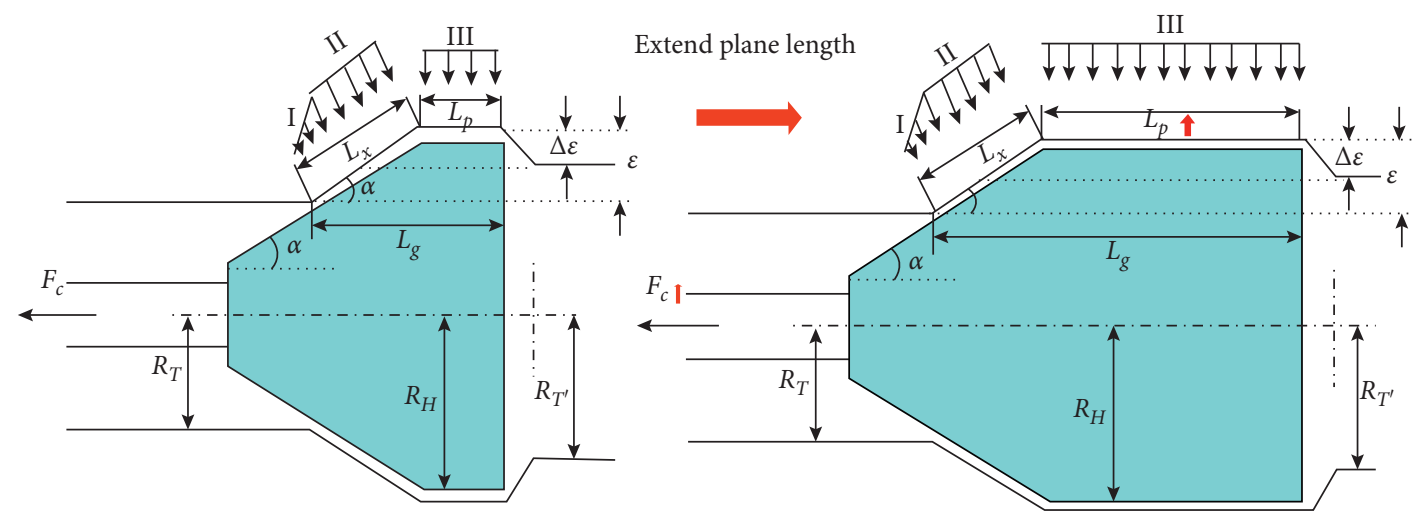

FIGURE 5: Increase of the plane length in a constant resistance body.
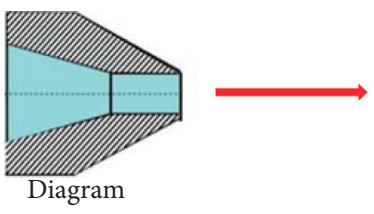

(a)
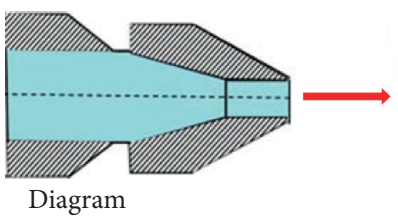

(c)

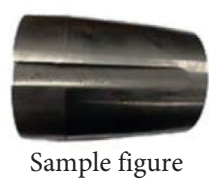

Sample figure

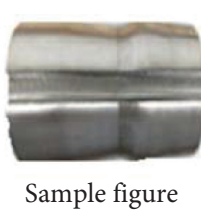

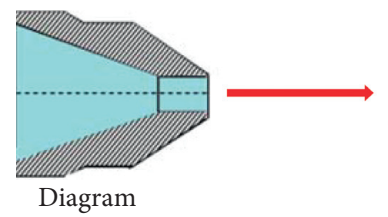

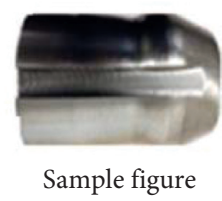

(b)

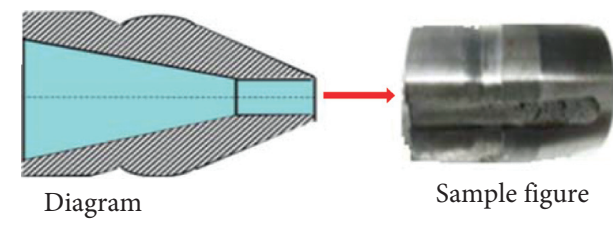

(d)

Figure 6: Constant resistance body. (a) Single-stage expansion. (b) First-stage friction + second-stage expansion. (c) First-stage expansion + second-stage expansion. (d) First-stage expansion + second-stage friction.

well as the stable state of their constant resistance were studied. Here, a comparison of their mechanical performances with those of other types of cables is presented.

\subsection{Experimental System and Test Specimens}

3.1.1. Experimental Specimen and Parameters. In the following static tensile experiment, an ordinary NPR anchor cable, with a deformation of $1000-2000 \mathrm{~mm}$, and a giant NPR anchor cable, with a deformation of $3000-4000 \mathrm{~mm}$, are investigated. As shown in Figure 7, a total of four groups of experiments were carried out. The radial size of the constant resistance body was $\Phi 121 \times 17$, due to the limitations given by its inner diameter, which affect the capacity of the bearing force. For this reason, single strands of $1 \times 9$ were employed and the constant resistance body was fixed.

The steel strand selected in this test is different compared to the one used to obtain the results in the early stage of this research. Moreover, the constant resistance of the NPR anchor cable during the static tensile test is larger than that measured during previous tests. The main parameters are shown in Table 1. The tensile strength, the maximum breaking force, the elongation, and the stress relaxation properties of the steel strand were determined during the tensile test.
After determining the geometrical size and the mechanical parameters of the strand, constant resistance bodies with different diameters were fabricated based on the dimensions of the constant resistance sleeve. While an NPR anchor with a deformation of $1000 \mathrm{~mm}$ adopts the original constant resistance body, an NPR anchor with a deformation of $2000 \mathrm{~mm}$ shows a constant resistance body, which is characterized by a one-stage and a two-stage expansion. The NPR anchor cable with a deformation of $3000 \mathrm{~mm}$ adopts a constant resistance body characterized by a one-stage expansion and a two-stage friction. The NPR anchor cable with a deformation of $4000 \mathrm{~mm}$ is, instead, characterized by a primary resistance and a secondary expansion of the constant resistance body, as shown in Table 2.

3.1.2. Experimental System. The experimental equipment used to carry out these tests is an HWL-2000 anchor cable tension tester, which is able to monitor the deformations of the constant resistance, and an NPR anchor cable automatic installation equipment, as shown in Figure 8.

3.2. Experimental Process. The experiment that was carried out consists of six steps: (1) the constant resistance body is marked; (2) an even layer of grease is applied over the 


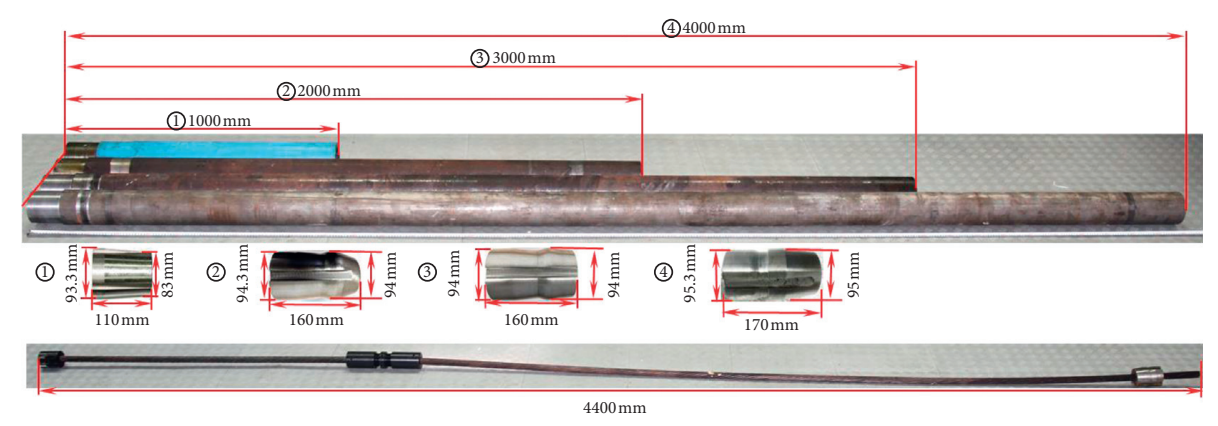

FIGURE 7: NPR anchor.

TABle 1: Mechanical features of the $1 \times 9$ prestressed strand.

\begin{tabular}{lcccccc}
\hline $\begin{array}{l}\text { Diameter } \\
(\mathrm{mm})\end{array}$ & $\begin{array}{c}\text { Tensile strength } \\
(\mathrm{MPa})\end{array}$ & $\begin{array}{c}\text { Maximum force } \\
(\mathrm{kN})\end{array}$ & $\begin{array}{c}\text { Stretching force } \\
(\mathrm{kN})\end{array}$ & $\begin{array}{c}\text { Elongation } \\
(\%)\end{array}$ & $\begin{array}{c}\text { Stress relaxation ability } \\
\text { Initial load/maximum } \\
\text { engineering pressure }\end{array}$ & $\begin{array}{c}\text { Stress relaxation } \\
\text { percentage after 1000h }\end{array}$ \\
\hline 18.24 & 2287 & 1200 & 900 & 3.5 & 0.7 & 2.5 \\
\hline
\end{tabular}

TABLE 2: Size of the constant resistance body and the constant resistor.

\begin{tabular}{|c|c|c|c|c|c|c|}
\hline \multirow{2}{*}{$\begin{array}{l}\text { Test } \\
\text { number }\end{array}$} & \multicolumn{3}{|c|}{$\begin{array}{c}\text { Constant resistance } \\
\text { body size }\end{array}$} & \multicolumn{3}{|c|}{$\begin{array}{l}\text { Constant resistance } \\
\text { sleeve size }(\mathrm{mm})\end{array}$} \\
\hline & Length (mm) & $\begin{array}{c}\text { Front diameter }(\mathrm{mm}) \\
\text { Preexperiment }\end{array}$ & $\begin{array}{c}\text { Rear } \\
\text { diameter }(\mathrm{mm})\end{array}$ & Length (mm) & $\begin{array}{c}\text { Inner } \\
\text { radius }(\mathrm{mm})\end{array}$ & $\begin{array}{c}\text { Outer } \\
\text { radius }(\mathrm{mm})\end{array}$ \\
\hline LS-1000 & 110 & 83 & 93.3 & 1000 & & \\
\hline LS-2000 & 160 & 94 & 94.3 & 2000 & & \\
\hline LS-3000 & 160 & 94 & 94 & 3000 & 87 & 121 \\
\hline LS-4000 & 170 & 95 & 95.3 & 4000 & & \\
\hline
\end{tabular}

constant resistance body; (3) the constant resistance body is connected to the steel strand; (4) the constant resistance body and the steel strand are secured via the constant resistance sleeve; (5) the connector located at the rear end of the constant resistance device is installed via an automatic installation process, and it is at this moment that the NPR anchor cable is successfully assembled; and (6) the NPR anchor cables are loaded into the experimental setup, and the steel wire is clamped via the front clamping device, while the rear clamping device clamps the anchor cable back end connector. Moreover, a certain prestress is applied, as shown in Figure 9. The control mode is set via the displacement stretching control on the microcomputer controller, and the tensile rate is set to $20 \mathrm{~mm} / \mathrm{min}$.

3.3. Experimental Results and Analysis. The mechanical displacement curve of the NPR anchor cable was obtained via the aforementioned experimental technique. The existing law of NPR anchor cable static tensile results with a deformation of $1000 \sim 4000 \mathrm{~mm}$ is analyzed. Moreover, the mechanical displacement curve and energy of the NPR cable with a deformation of $1000 \mathrm{~mm}$ are represented via a columnar section, as shown in Figure 10. Section I shows in the elastic deformation stage. During this stage, the constant resistance is around $490 \mathrm{kN}$ and the deformation is about $80 \mathrm{~mm}$. During Section II, the constant resistance fluctuates in a stable fashion with an average constant resistance of $495 \mathrm{kN}$ and a deformation of about $700 \mathrm{~mm}$. During Section III, the cable fails after a limited amount of time. The final deformation is around $850 \mathrm{~mm}$, the theoretical deformation is $1000 \mathrm{~mm}$, and the final energy absorption is $4.21 \times 10^{5} \mathrm{~J}$.

The mechanical displacement curve and the energy columnar section of the NPR anchor with a deformation of $2000 \mathrm{~mm}$ are shown in Figure 11. Section I shows the elastic deformation stage, where the final constant resistance is around $420 \mathrm{kN}$ and the deformation is about $80 \mathrm{~mm}$. Section II shows the steady fluctuation stage of the constant resistance with a maximum and a minimum constant resistance of $631 \mathrm{kN}$ and $467.3 \mathrm{kN}$, respectively. In addition, the average constant resistance measured is $535 \mathrm{kN}$. Section III shows the failure stage, where the constant resistance acquires a theoretical deformation of $2000 \mathrm{~mm}$ and the actual deformation measured is $1900 \mathrm{~mm}$. The final average energy is $1.07 \times 10^{6} \mathrm{~J}$.

Figures 10 and 11 show that there is a uniform fluctuation of the upper and of the lower level of the constant resistance curve. This phenomenon is related to the structure and the size of the constant resistance body. The mechanical displacement curve and the energy columnar section of the NPR anchor with a deformation of $3000 \mathrm{~mm}$ are reported in Figure 12.

Via the analysis of Figure 12, Section I, which corresponds to the elastic deformation, can be obtained. In this 


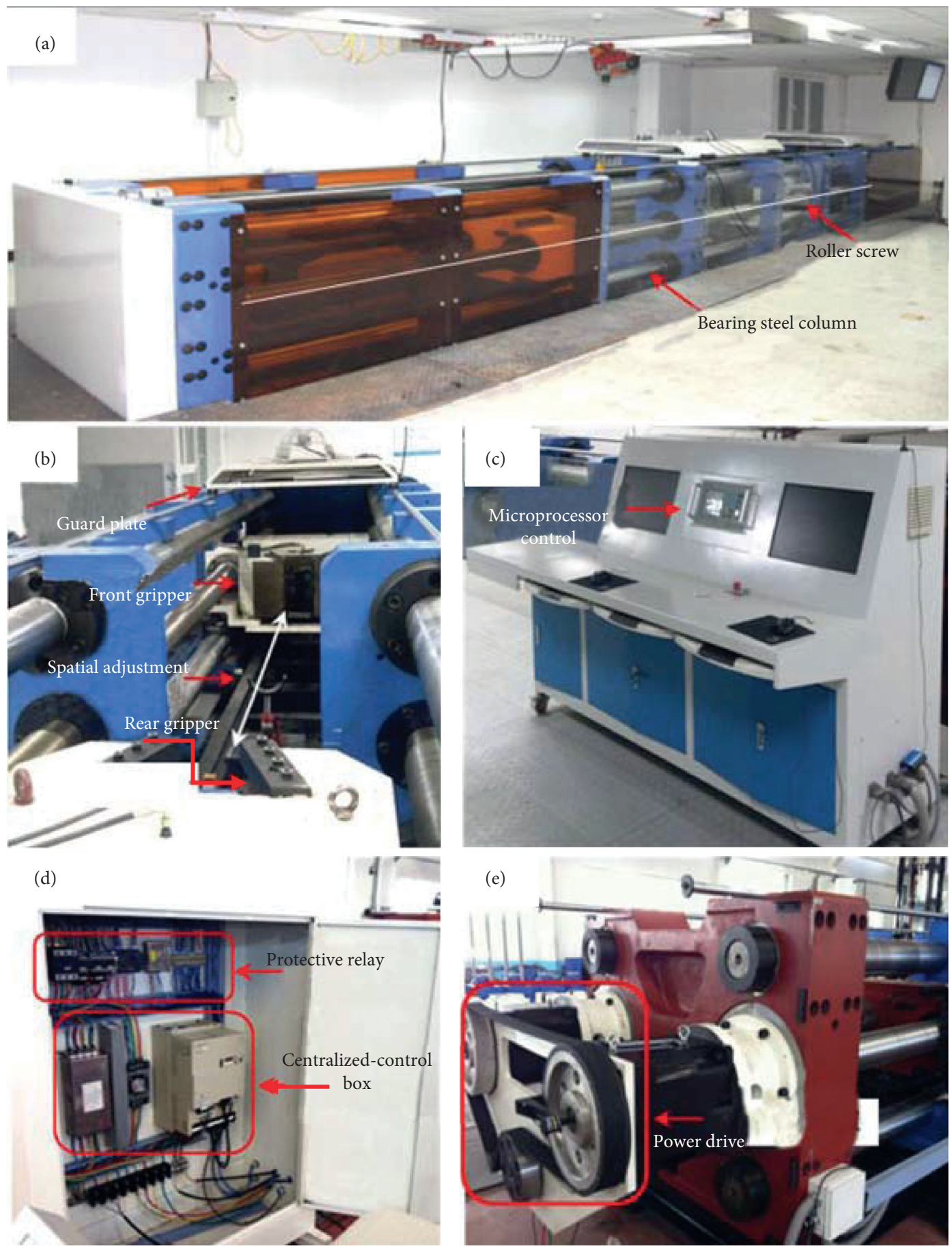

FIGURE 8: NPR anchor tensile testing machine: (a) host frame; (b) work platform; (c) experimental control system; (d) electrical control system; (e) motion transfer system.

state, the final constant resistance and the deformation measure are $550 \mathrm{kN}$ and $180 \mathrm{~mm}$, respectively. Even after the test, the constant resistance device is cut laterally, and it is found that the inner wall of the constant resistance device in this section is seriously damaged.

The results show that the inner wall of the constant resistance device is seriously damaged. A few of the metal fragments are scraped off after the test, and this section is compared with other parts of the constant resistance device.
The findings show that the failure was generated along the axis of the constant resistance device. This is the most important cause of fluctuations, which can affect the constant resistance. Section III comprises the failure stage. Despite its theoretical deformation was calculated to be $3000 \mathrm{~mm}$, the actual deformation and the final average energy are $2740 \mathrm{~mm}$ and $1.57 \times 10^{6} \mathrm{~J}$, respectively. The mechanical displacement curve and the energy columnar section of the NPR anchor cable with a deformation of 


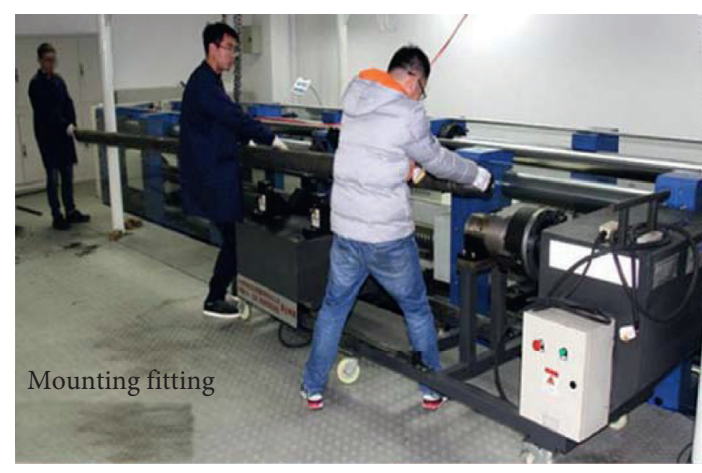

(a)

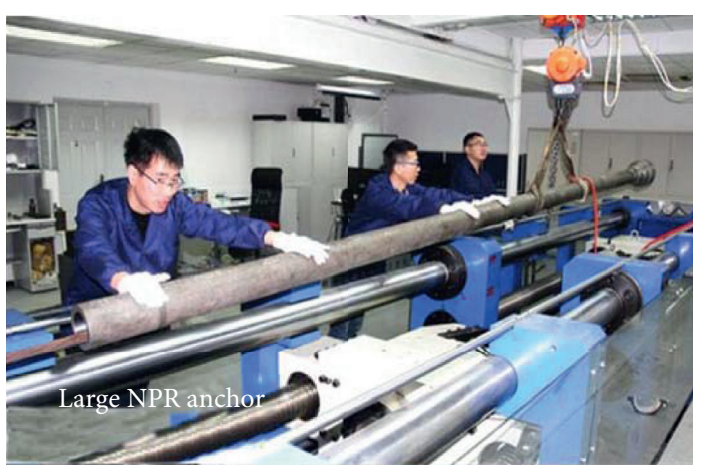

(b)

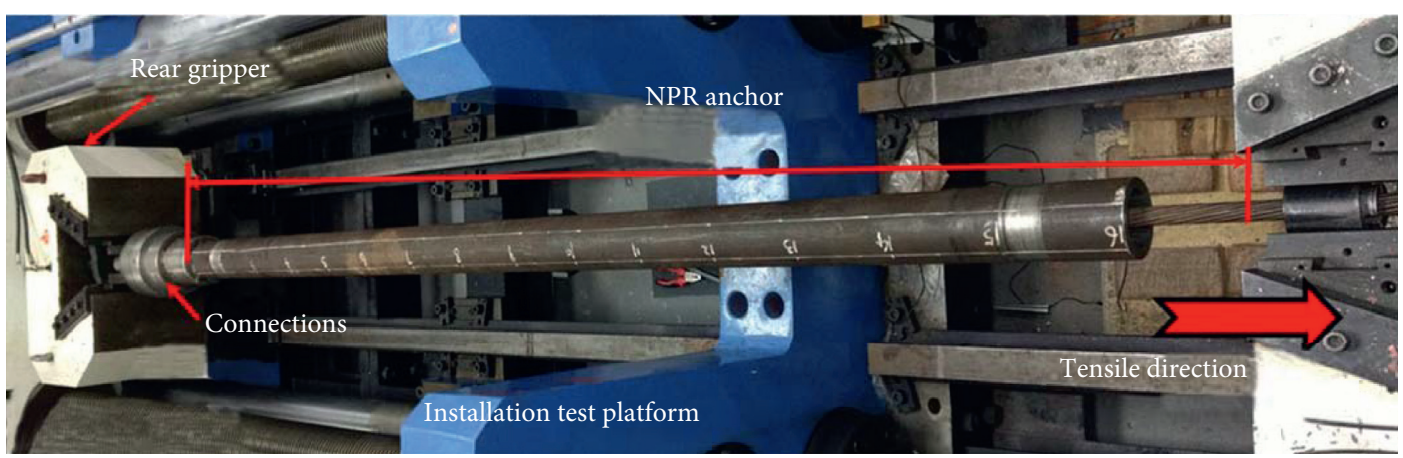

Rear gripper

(c)

Figure 9: Complete installation.

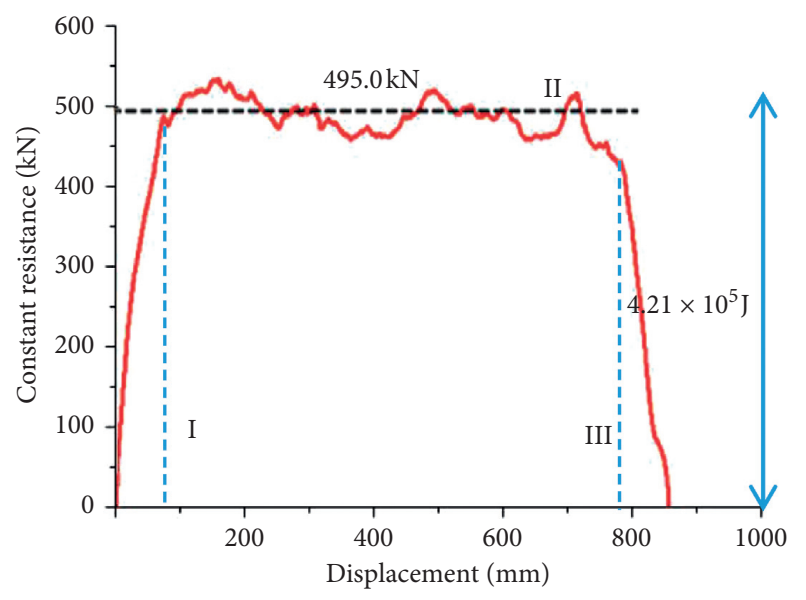

FIGURE 10: NPR anchor experimental curve (with a deformation of $1000 \mathrm{~mm}$ ): mechanical curve.

$4000 \mathrm{~mm}$ are shown in Figure 13. The final constant resistance and the deformation of the first stage are $380 \mathrm{kN}$ and $260 \mathrm{~mm}$, respectively. The constant resistance fluctuation at higher stages progressively increases, until the constant resistance reaches $800 \mathrm{kN}$. The minimum value of the constant resistance is $629.8 \mathrm{kN}$ and the average constant resistance is $723 \mathrm{kN}$ during the movement of Section IV of the constant resistance body. The failure stage refers to the third type of anchor cable, characterized by a theoretical deformation of $4000 \mathrm{~mm}$, but an actual deformation of

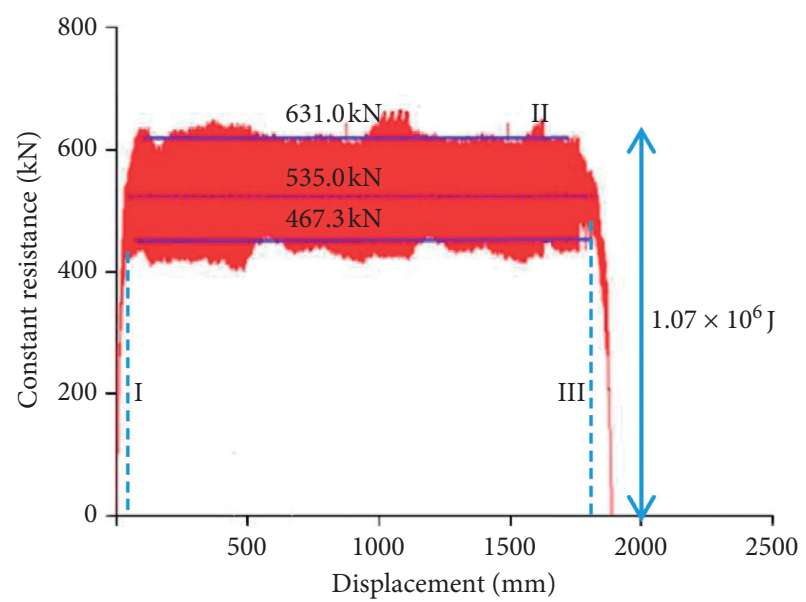

FIGURE 11: NPR anchor experimental curve (with a deformation of $2000 \mathrm{~mm}$ ): mechanical curve.

$3980 \mathrm{~mm}$, a final average energy of $2.75 \times 10^{6} \mathrm{~J}$, and a maximum energy of $3.2 \times 10^{6} \mathrm{~J}$.

Figure 13 shows the anchor cables' characteristic curve. It presents increasing and uniform fluctuations on Sections I and IV of the constant resistance. This result can be explained via the shrinking of the inner diameter of the constant resistance.

In order to visually compare the mechanical states of the NPR anchor cables with their deformations ranging from $1000 \mathrm{~mm}$ to $4000 \mathrm{~mm}$, the mechanical curves and the energy 


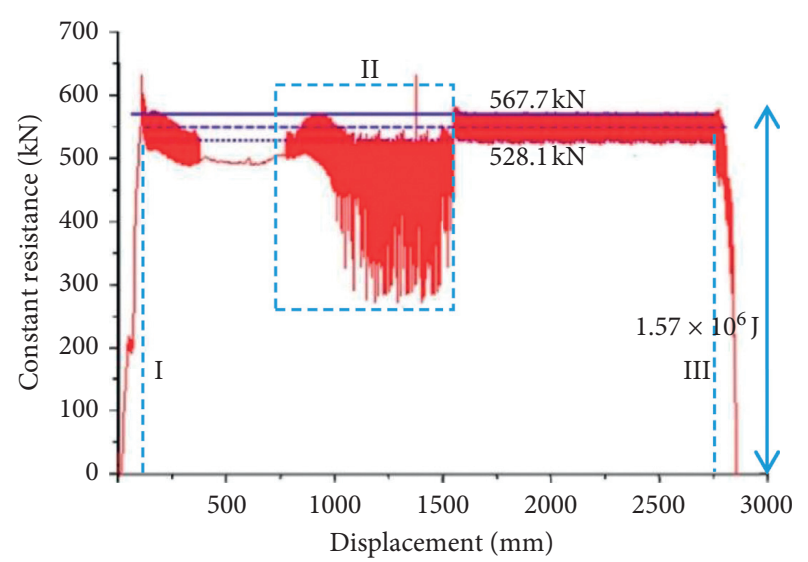

FIGURE 12: NPR anchor experimental curve (with a deformation of $3000 \mathrm{~mm}$ ): mechanical curve.

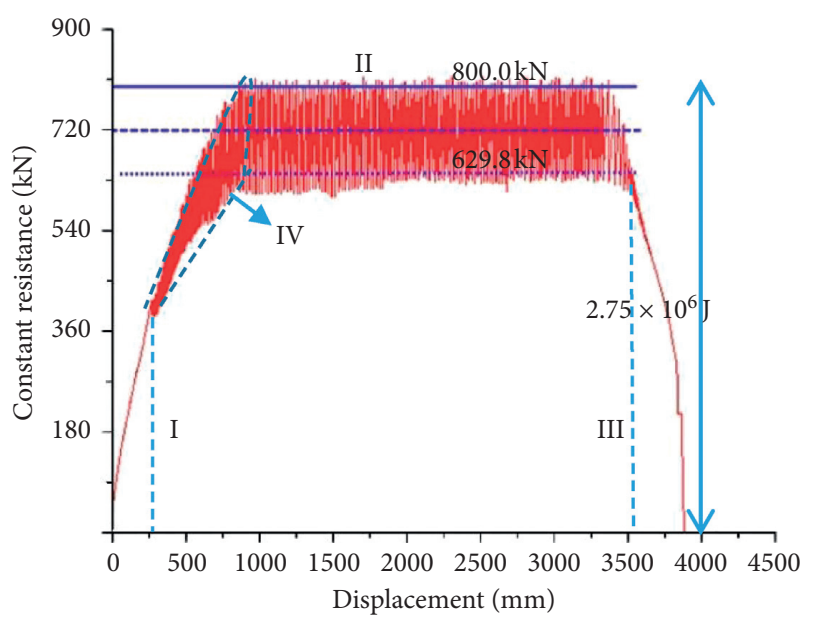

FIGURE 13: NPR anchor experimental curve (with a deformation of $4000 \mathrm{~mm}$ ): mechanical curve.

diagram of the four NPR anchor cables are placed in the same coordinate system in Figure 14.

From the analysis of Figure 14, one can define four characteristics for the NPR anchor cables: (1) The constant resistance of an NPR anchor cable is related to the size of the constant resistance body. (2) The constant resistance fluctuation rule for an NPR anchor cable is relevant to the analysis of the structure of the constant resistance body. A single expansion is adopted by the constant resistance body of the NPR anchor cable with a deformation of $1000 \mathrm{~mm}$, and this leads to irregular fluctuations in the constant resistance curve. The NPR anchor cables with a deformation of $2000 \mathrm{~mm}$ and $4000 \mathrm{~mm}$ are characterized by more regular fluctuations, and they adopt a two-stage expansion constant resistance body. A first-order expansion and a second-order friction are adopted by the NPR anchor cable with a deformation of $3000 \mathrm{~mm}$. The fluctuation of its constant resistance curve shows a certain regularity with a little fluctuation range. (3) The coaxiality of the NPR anchor cable constant resistance device has a certain impact on the constant resistance, as shown in the NPR anchor cable mechanics curve with a deformation of $3000 \mathrm{~mm}$. (4) Under the premise of maintaining a constant resistance or increasing the constant resistance, upon the increase of the NPR anchor cable deformation, its energy absorption increases significantly.

\section{Engineering Application and Result Analysis}

4.1. Engineering Situation. The Changdifang Reservoir is located in the Nanlang River, a tributary of the upstream of the Zhanda River in the north of Yingjiang County, Dehong Prefecture, Yunnan Province. The dam site has a normal water storage level of $2188.87 \mathrm{~m}$, a top elevation of $2191.1 \mathrm{~m}$, a maximum dam height of $37.5 \mathrm{~m}$, and a storage capacity of 13.114 million $\mathrm{m}^{3}$. This reservoir is equipped with a town flood control measure and is used for agricultural irrigation and the town water supply of medium-sized water conservancy projects. According to the field survey, only Xiongjiashan near the dam site has a large source of weak weathered fossil materials and is the only stone source near the dam site of Changdifang Reservoir (within $5 \mathrm{~km}$ ), meeting the dam construction demand.

The Xiongjiashan quarry is located downstream of the intersection of the Hexinba River and the Nanlang River downstream of the tributary dam site and is about $36,900 \mathrm{~m}^{2}$ area. The southwest end of the quarry is partially steep near the river. The rock outcrops are mostly weakly weathered bedrocks with thin overburdens.

On February 9, 2018, during the mining process of the Xiongjiashan quarry, the top excavation surface was affected by unloading and the steep-inclined structural planes along the slope. A ring-shaped tensile crack appeared along an elevation of $1963 \mathrm{~m}$, and the crack extended downward along the slope to a high level. $1918 \mathrm{~m}$ platform formed a slump body with a vertical height of $53 \mathrm{~m}$, a maximum lateral width of $\sim 92 \mathrm{~m}$, and a maximum longitudinal slope length of $\sim 70 \mathrm{~m}$. As of February 22, 2018, the vertical seating height of the $1963 \mathrm{~m}$ position at the top of the slump body was approximately $2.5-3 \mathrm{~m}$; affected by the June 29,2018 , earthquake and sustaining heavy rainfall, the slope deformation and crack development of the Xiongjiashan quarry accelerated; on July 1, 2018, the top crack at the top of the quarry widened about $6 \mathrm{~cm}$ to $7 \mathrm{~cm}$, four new cracks appeared to the left of the top, and a new crack appeared (the excavated support slope surface), which was connected to the original crack and developed to a $1938 \mathrm{~m}$ platform.

4.2. Monitoring Point Design. After the Xiongjiashan quarry experienced two concentrated supports, its antisliding force on the slope still could not resist the sliding force caused by the prolonged rainfall and excavation. Slope cracks continued to appear and urgently needed an effective slope monitoring, warning, and reinforcement method for uninterrupted landslide monitoring of the quarry slope to ensure the safety of life and property of the staff; therefore, the NPR Newton force monitoring and early warning system was introduced. According to the landslide scale of the Xiongjiashan quarry and the target of monitoring and early 


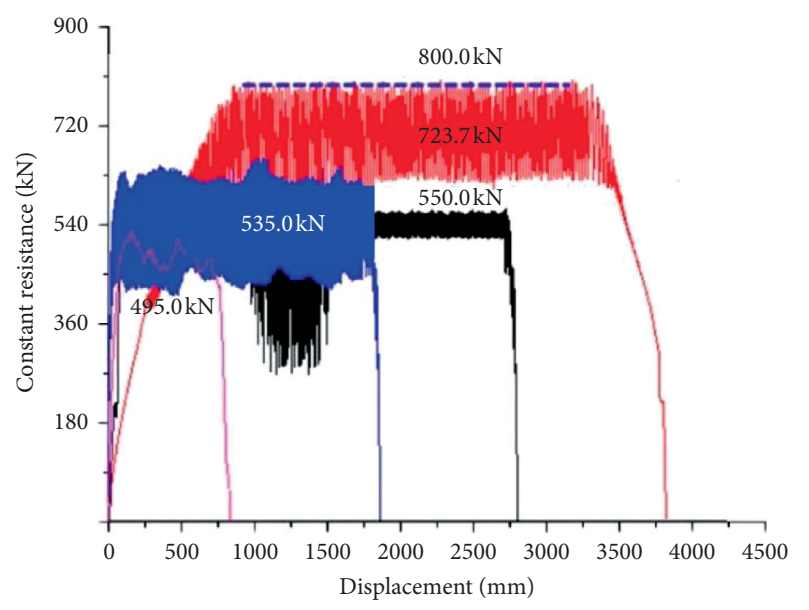

(a)

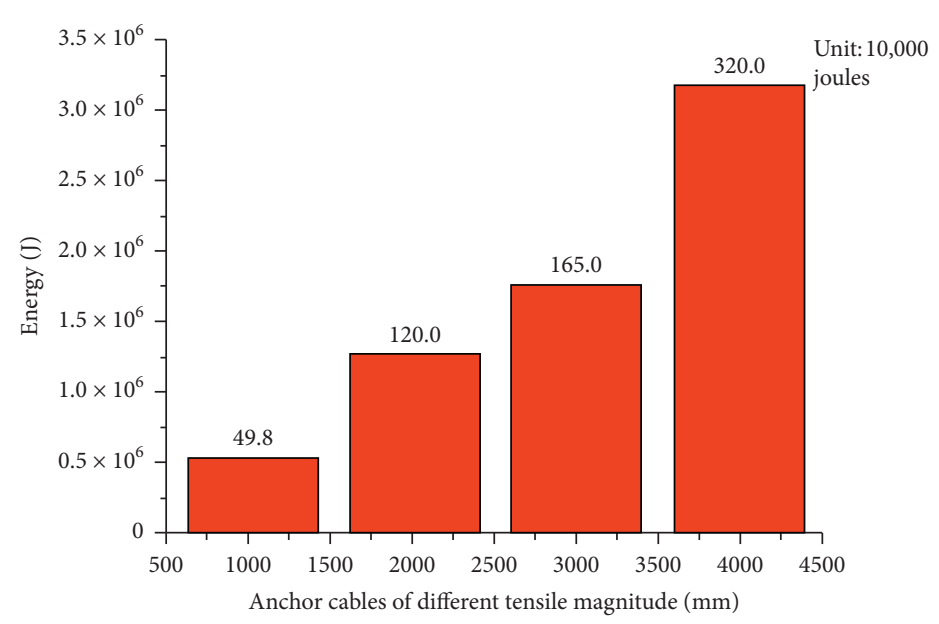

(b)

FIGURE 14: NPR anchor experimental curve (with a deformation of 1000-4000 mm): (a) mechanical curve; (b) energy diagram.

warning control, a total of four NPR Newton force monitoring points and 12 displacement monitoring points were installed on the landslide. Figure 15(a) shows the plan distribution of the four monitoring points, and Figure 15(b) shows the cross-sectional characteristic along the $\mathrm{M}-\mathrm{M}^{\prime}$ section line in the monitoring area.

4.3. Analysis of Newton Force Warning Time of Landslide Process. On January 10, 2019, all monitoring points began normal operation. According to the landslide warning criteria and warning threshold, as shown in Table 3, the NPR Newton force remote monitoring and early warning system released the "2019-0728 landslide" in the Xiongjiashan quarry in a timely manner through the network platform based on the long-term, medium-term, and proslide warning information. The proslide warning was issued on July 27, 2019, $20 \mathrm{~h}$ in advance. This No. 2 NPR Newton force monitoring point is located in the middle of the monitoring area, and the deformation of the NPR anchor cable used is up to $3 \mathrm{~m}$. Compared to the other three monitoring points, the monitoring of the entire slope is representative. Therefore, the monitoring curve of the No. 2 NPR Newton force monitoring point was selected as the representative for analysis. The specific analysis is shown in Figure 16.

Before July 20, 2019, the monitoring curve slowly increased, followed by a sudden increase, but $\Delta \mathrm{T}$ was $<200 \mathrm{kN}$. Within the range allowed by the warning threshold, the monitored slope was relatively stable, and the monitoring system did not issue any warning information.

According to the Newton force monitoring and early warning level, the joint monitoring team released the yellow long-term warning information in the area. At 17:07 on July 24, 2019 (point A in Figure 16(a)), the Newton force increased cumulatively by $200 \mathrm{kN}$. No new cracks appeared in the entire slope, as revealed by the system, and the stope decision level strengthened the grasp of the stability of the slope by increasing the monitoring frequency of the Newton force monitoring points.

Due to the heavy rainfall in the period July 25-27, 2019, the monitoring curve suddenly increased, and the Newton force increased by more than $400 \mathrm{kN}(\Delta \mathrm{T}>300 \mathrm{kN})$. According to the Newton force monitoring and early warning level, the monitoring team at $04: 15$ on July 27, 2019 (point B in Figure 16(a)), released the orange medium-term early warning information in the area. The investigation of the scene indicated that, below the $1918 \mathrm{~m}$ platform of the stope with an excavator in operation, the straight distance between the operation spot and the No. 2 monitoring point was approximately $50 \mathrm{~m}$. After the new and the old cracks widened, the stope decision level immediately ordered all large machinery and construction workers below the stope to evacuate the site and took corresponding risk prevention measures. Cracks were observed under the concrete anchor pier of the slope, exhibiting a gradually extending trend from the bottom to the top and from the left to the right.

Based on the Newton force monitoring and early warning level, at $14: 48$ on July 27, 2019 (point C in Figure 16(b)), only $5 \mathrm{~h}$ after the orange warning information was released in the area, the monitoring curve showed a sudden decline in slope. The system issued a warning to the stope staff and monitors in the area. The stope decision level required all the personnel and large and small machinery to leave the site together. The slope crack suddenly widened, and lifting on the left and sinking on the right occurred on the whole.

Via the analysis of Figure 16(b), at $17: 24$ on July 27, the monitoring curve dropped to the lowest point and the Newton force changed constantly. At 10:29 on July 28 (point D in Figure 16(b)), the slope exhibited slip disintegration with three loud noises. Severe damage occurred at the top, middle, and side edges of the slope with the sliding of the slope body at the bottom, and the top of the slope body presented slipping-tension failure. A large wrong platform 


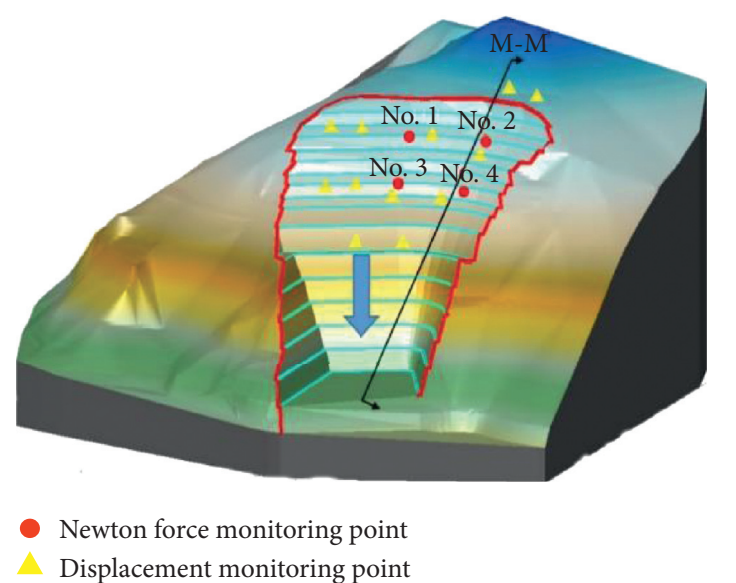

(a)

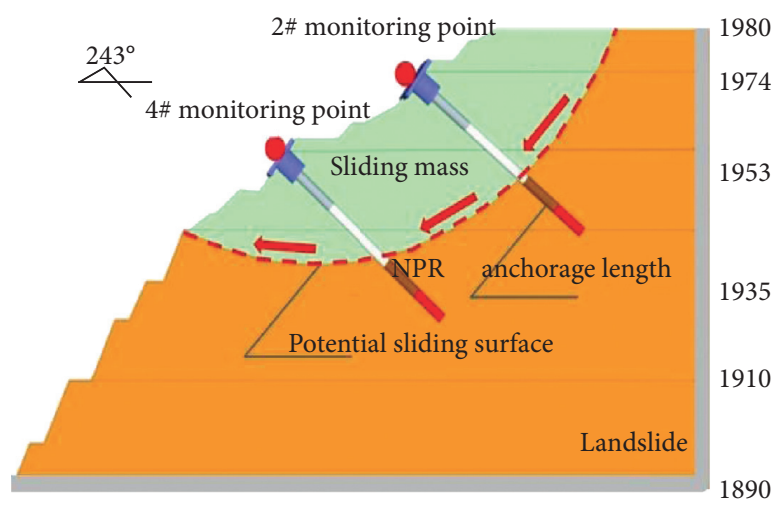

(b)

FIGURE 15: Design of landslide monitoring points in the Xiongjiashan stone material. (a) Distribution characteristics of monitoring points. (b) Cross section along the M-M' section.

TABle 3: Deep Newton force monitoring warning level and warning criteria.

\begin{tabular}{|c|c|c|c|c|c|}
\hline $\begin{array}{l}\text { Warning } \\
\text { level }\end{array}$ & Critical forecast & $\begin{array}{c}\text { First-level criterion: Newton force } \\
T(\mathrm{kN})\end{array}$ & \multicolumn{3}{|c|}{ Secondary criterion: Newton force increase $\Delta T(\mathrm{kN})$} \\
\hline Blue & Stability warning & $0-200$ & \multirow{2}{*}{$\begin{array}{l}20-50 \text { rise to yellow } \\
\text { Newton force rise } \\
\text { (burst) }\end{array}$} & \multirow{2}{*}{$\begin{array}{c}50-100 \text { rise to } \\
\text { orange }\end{array}$} & \multirow{3}{*}{$\begin{array}{c}>100 \text { rise to } \\
\text { red }\end{array}$} \\
\hline Yellow & Substability warning & $200-400$ & & & \\
\hline Orange & Close slip warning & $400-600$ & \multicolumn{2}{|c|}{ Newton force rise (burst) } & \\
\hline Red & $\begin{array}{l}\text { Warning time of the } \\
\text { landslide }\end{array}$ & More than 600 & \multicolumn{3}{|c|}{ Sudden drop of Newton force } \\
\hline
\end{tabular}

Note. Newton force $T=T_{\mathrm{n}}-T_{0}$; Newton force increase $\Delta T=T_{\mathrm{n}}-T_{\mathrm{n}-1}$; initial prestress $T_{0}=200 \mathrm{kN}$.

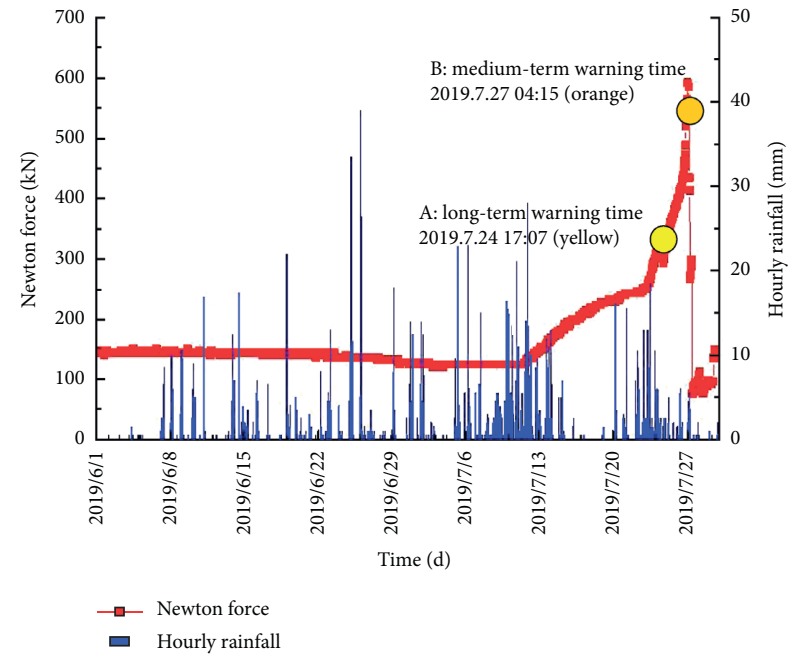

(a)

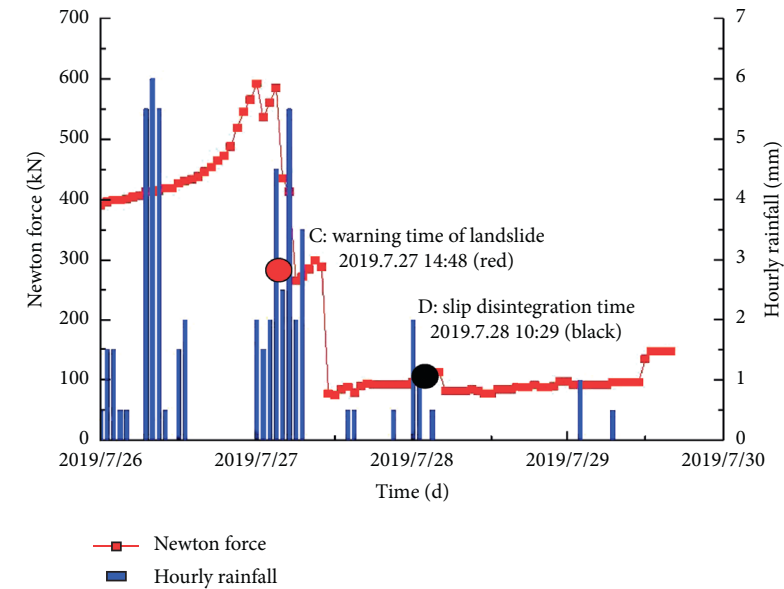

(b)

Figure 16: Coupling monitoring curves of the No. 2 warning system. (a) No. 2 monitoring point curve. (b) No. 2 warning of the landslide monitoring point warning curve.

appeared at the back edge. Slipping-collapse failure occurred in the middle of the slope.

At the site, a landslide occurred in the $1918-2000 \mathrm{~m}$ range of the platform length, with the vertical height difference of the sliding mass being approximately $200 \mathrm{~m}$ and the length from the south to the north being approximately $180 \mathrm{~m}$. The landslide characteristics are shown in Figure 17. 


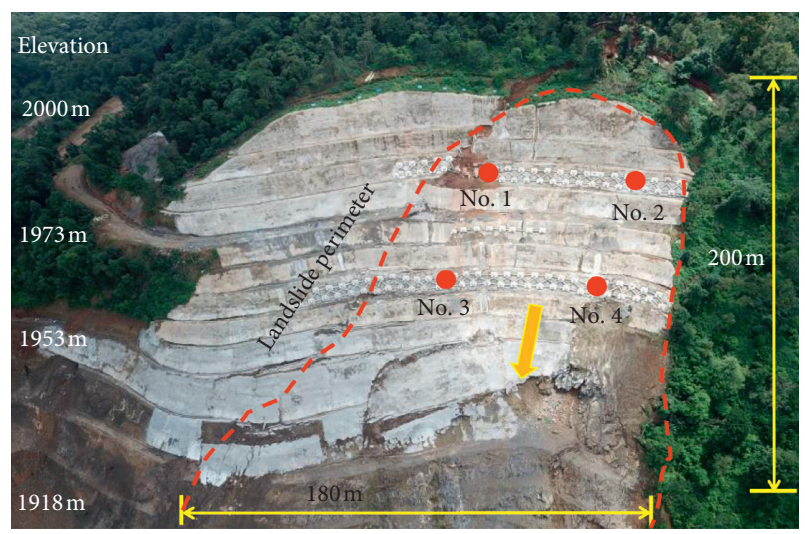

FIGURE 17: Characteristics of the "2019-0728” landslide.

The above results show that, since the warning system for NPR-3000 mm Newton force monitoring was adopted to provide timely warning for the whole process of the "20190728 landslide," no casualties or property losses occurred. The warning process not only verifies the NPR cable's mechanical properties of large deformation, high constant resistance, and no tensile failure but also shows its wide application value in strengthening, preventing, monitoring, and warning of slope failure.

\section{Conclusion}

Based on the scientific concept of "predicting deep geological fault tectonic activity and controlling local geological activity faults" as the core proposed by He Manchao, this work aims to develop giant NPR anchor cables which can stand a great deformation and a relatively stable fluctuation of the constant resistance within a certain range. This study is based on the NPR anchor cable with a deformation of $1000-2000 \mathrm{~mm}$. The results of this work elucidate the structure of the constant resistance body as follows:

(1) In order to increase the constant resistance, the constant resistance body structure is modified and three kinds of constant resistance bodies with new characteristics can be obtained. Their characteristics are the following: first-stage friction and secondstage expansion constant resistance body; first-stage expansion and second-stage expansion constant resistance body; and first-stage expansion and second-stage friction constant resistance body.

(2) The constant resistance of an NPR anchor cable is related to the size of the constant resistance body. Moreover, the fluctuation trend of the constant resistance can be associated with the structure of the constant resistance body.

(3) The constant resistance value of the giant NPR anchor cable with a deformation in the range of $3000-4000 \mathrm{~mm}$ is $550-723.7 \mathrm{kN}$, while the average energy absorption is $1.57 \times 10^{6}-2.75 \times 10^{6} \mathrm{~J}$ and the maximum energy is $3.2 \times 10^{6} \mathrm{~J}$. These measurements were obtained via a static tensile test.
(4) The monitoring results of a landslide at the Xiongjiashan quarry show that, with the adoption of a monitoring and warning system for NPR Newton force and proper analysis on the coupling monitoring curve, we can issue timely and effective warning for the whole process of the landslide. It not only verifies the NPR cable's mechanical properties of large deformation, high constant resistance, and no tensile failure but also shows its application value in strengthening, preventing, monitoring, and warning of slope failure.

(5) The new constant resistance body is built in the NPR anchor cable. Its resistance and its energy absorption values are compared with the original values, and the result demonstrates that the giant NPR anchor cable shows superior mechanical properties upon the static tensile test. This provides a reliable technical support for the application of NPR anchor cables in deep geological faults.

\section{Data Availability}

The data used to support the findings of this study are available from the corresponding author upon request.

\section{Conflicts of Interest}

The authors declare that there are no conflicts of interest regarding the publication of this article.

\section{Acknowledgments}

This work was supported by the Shandong Province Natural Science Foundation (ZR2017PD011). Academician Manchao He provided helpful comments for the current manuscript, who is gratefully acknowledged.

\section{References}

[1] Q. X. Qi, Impact and Pressure Theory and Technology, China University of Mining and Technology Press, Beijing, China, 2008.

[2] B. Shen, "Coal mine roadway stability in soft rock: a case study," Rock Mechanics and Rock Engineering, vol. 47, no. 6, pp. 2225-2238, 2014.

[3] G. S. Esterhuizen, D. F. Gearhart, and I. B. Tulu, "Analysis of monitored ground support and rock mass response in a longwall tailgate entry," International Journal of Mining Science and Technology, vol. 28, no. 1, pp. 43-51, 2018.

[4] Z. Chun, T. Zhigang, Y. Sen, and Z. Shuai, "V shaped gully method for controlling rockfall of high-steep slope in China," Bulletin of Engineering Geology and the Environment, vol. 78, no. 4, pp. 2731-2747, 2019.

[5] N. Wu, Z. Liang, J. Zhou, and L. Zhang, "Energy evolution characteristics of coal specimens with preformed holes under uniaxial compression," Geomechanics and Engineering, vol. 20, pp. 55-66, 2020.

[6] Z. Qin, H. Fu, and X. Chen, "A study on altered granite mesodamage mechanisms due to water invasion-water loss cycles," Environmental Earth Sciences, vol. 78, no. 14, p. 428, 2019. 
[7] J. Wang, S.-C. Li, L.-P. Li, P. Lin, Z.-H. Xu, and C.-L. Gao, "Attribute recognition model for risk assessment of water inrush," Bulletin of Engineering Geology and the Environment, vol. 78, no. 2, pp. 1057-1071, 2019.

[8] F. Ren, C. Zhu, and M. He, "Moment tensor analysis of acoustic emissions for cracking mechanisms during schist strain burst," Rock Mechanics and Rock Engineering, vol. 53, no. 1, pp. 153-170, 2019.

[9] A. Li, Y. Liu, F. Dai, K. Liu, and M. D. Wei, "Continuum analysis of the structurally controlled displacements for largescale underground caverns in bedded rock masses," Tunnelling and Underground Space Technology, vol. 97, Article ID 103288, 2020

[10] W. D. Ortlepp, Yieldable Rock Bolts for Shock Loading and Grouted Bolts for Faster Rock Stabilization, pp. 12-17, Mines Magazine, Colorado School of Mines, Golden, CO, USA, 1970.

[11] W. D. Ortlepp, "Considerations in the design of support for deep hard rock tunnels," in Proceedings of the Fifth Congress of the International Society for Rock Mechanics, pp. 179-187, Melbourne, Australia, April 1983.

[12] T. F. Herbst, "Yieldable roof support for mines," in Proceedings of the 31st U. S. Symposium, pp. 807-814, Brookfield, WI, USA, June 1990.

[13] P. K. Kaiser and D. R. McCreath, "Evaluation of current support practices in burst-prone ground and preliminary guidelines for Canadian hard rock mines," in Proceedings of the International Symposium on Rock Support, pp. 611-619, Sudbury Canada, June 1992.

[14] A. Ansell, "Dynamic testing of steel for a new type of energy absorbing rock bolt," Journal of Constructional Steel Research, vol. 62, no. 5, pp. 501-512, 2006.

[15] F. Lin, W. Mengjun, W. Guangdi, and C. Peng, "Comparative analysis on stress state of submerged floating tunnels in different anchor cable arrangement modes," in Proceedings of 2nd International Symposium on Submerged Floating Tunnels and Underwater Tunnel Structures, pp. 279-287, Chongqing, China, 2016.

[16] Z. G. Tao, F. Zhao, H. J. Wang, H. J. Zhang, and Y. Peng, "Innovative constant resistance large deformation bolt for rock support in high stressed rock mass," Arabian Journal of Geosciences, vol. 10, p. 341, 2017.

[17] K. E. Evans and A. Alderson, "Auxetic materials: functional materials and structures from lateral thinking!," Advanced Materials, vol. 12, no. 9, pp. 617-628, 2000.

[18] K. E. Evans, A. Alderson, and F. R. Christian, "Auxetic twodimensional polymer networks. An example of tailoring geometry for specific mechanical properties," Journal of the Chemical Society, Faraday Transactions, vol. 91, no. 16, pp. 2671-2680, 1995.

[19] R. Ponowicz and D. Miedzińska, "Numerical and experimental research on polyisocyanurate foam," Computational Materials Science, vol. 64, pp. 126-129, 2012.

[20] W. B. Yang, X. Yang, and Z. M. Li, "Structure and properties of negative Poisson's ratio materials," Science and Engineering, vol. 11, pp. 15-19, 2001.

[21] H. Manchao, X. Jia, M. Coli, E. Livi, and L. Sousa, "Experimental study of rockbursts in underground quarrying of Carrara marble," International Journal of Rock Mechanics and Mining Sciences, vol. 52, pp. 1-8, 2012.

[22] M. He, W. Gong, J. Wang et al., "Development of a novel energy-absorbing bolt with extraordinarily large elongation and constant resistance," International Journal of Rock Mechanics and Mining Sciences, vol. 67, pp. 29-42, 2014.
[23] Y. Zhang, H. Li, Q. Sheng, K. Wu, and G. Chen, "Real time remote monitoring and pre-warning system for highway landslide in mountain area," Journal of Environmental Sciences, vol. 23, pp. S100-S105, 2011.

[24] J. Yang, Z. Tao, B. Li, Y. Gui, and H. Li, "Stability assessment and feature analysis of slope in nanfen open pit iron mine," International Journal of Mining Science and Technology, vol. 22, no. 3, pp. 329-333, 2012.

[25] H. Man-Chao, W. Jiong, S. Xiao-Ming, and Y. Xiao Jie, "Mechanics characteristics and applications of prevention and control rock brusts of the negative poisson's ratio effect anchor," Journal of the China Coal Society, vol. 39, pp. 214-221, 2014.

[26] E. Zieniuk and K. Szerszeń, “A separation of the boundary geometry from the boundary functions in PIES for 3D problems modeled by the Navier-Lamé equation," Computers \& Mathematics with Applications, vol. 75, no. 4, pp. 10671094, 2018.

[27] M. M. Chaudhri, “The Love equation for the normal loading of a rigid cone on an elastic half-space: no need for a modification," Philosophical Magazine Letters, vol. 97, no. 9, pp. 343-349, 2017. 